\title{
Combination of Cross-Sectional and Molecular Imaging Studies in the Localization of Gastroenteropancreatic Neuroendocrine Tumors
}

\author{
Christos Toumpanakis $^{\mathrm{a}}$ Michelle K. Kim ${ }^{\mathrm{b}}$ Anja Rinke ${ }^{\mathrm{c}}$ Deidi S. Bergestuen ${ }^{d}$ \\ Christina Thirlwell $^{\mathrm{a}}$ Mohid S. Khan ${ }^{\mathrm{a}}$ Ramon Salazar $^{\mathrm{e}}$ Kjell Oberg $^{f}$ \\ ${ }^{a}$ Neuroendocrine Tumour Unit, Royal Free Hospital, London, UK; ${ }^{b}$ Department of Gastroenterology, Mount Sinai School \\ of Medicine, New York, N.Y., USA; ' ${ }^{2}$ Department of Gastroenterology, Philipps University Marburg, Marburg, Germany;

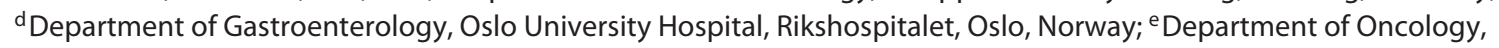 \\ Institut Català d'Oncologia, Barcelona, Spain; ${ }^{\mathrm{f}}$ Department of Endocrine Oncology, University Hospital, Uppsala, Sweden
}

\section{Key Words}

Gastroenteropancreatic neuroendocrine tumors .

Molecular imaging · Somatostatin receptor scintigraphy ·

Positron emission tomography

\begin{abstract}
Molecular imaging modalities exploit aspects of neuroendocrine tumors (NET) pathophysiology for both diagnostic imaging and therapeutic purposes. The characteristic metabolic pathways of NET determine which tracers are useful for their visualization. In this review, we summarize the diagnostic value of all available molecular imaging studies, present data about their use in daily practice in NET centers globally, and finally make recommendations about the appropriate use of those modalities in specific clinical scenarios. Somatostatin receptor scintigraphy (SRS) continues to have a central role in the diagnostic workup of patients with NET, as it is also widely available. However, and despite the lack of prospective randomized studies, many NET experts predict that Gallium-68 $\left({ }^{68} \mathrm{Ga}\right)$-DOTA positron emission tomography (PET) techniques may replace SRS in the future, not only because of their technical advantages, but also because they are superior in patients with small-volume disease, in patients with skeletal metastases, and in those with occult primary tumors. Carbon-11 $\left({ }^{11} \mathrm{C}\right)$-5-hydroxy-L-tryptophan (5-
\end{abstract}

HTP) PET and ${ }^{18} \mathrm{~F}$-dihydroxyphenylalanine $\left({ }^{18} \mathrm{~F}\right.$-DOPA) PET are new molecular imaging techniques of limited availability, and based on retrospective data, their sensitivities seem to be inferior to that of ${ }^{68} \mathrm{Ga}$-DOTA PET. Glucagon-like-peptide-1 (GLP-1) receptor imaging seems promising for localization of the primary in benign insulinomas, but is currently available only in a few centers. Fluorine-18 $\left({ }^{18} \mathrm{~F}\right)$-fluorodeoxyglucose ( $\left.{ }^{18} \mathrm{~F}-\mathrm{FDG}\right)$ PET was initially thought to be of limited value in NET, due to their usually slow-growing nature. However, according to subsequent data, ${ }^{18} \mathrm{~F}$-FDG PET is particularly helpful for visualizing the more aggressive NET, such as poorly differentiated neuroendocrine carcinomas, and well-differentiated tumors with Ki67 values $>10 \%$. According to limited data, ${ }^{18} \mathrm{~F}-\mathrm{FDG}$-avid tumor lesions, even in slow-growing NET, may indicate a more aggressive disease course. When a secondary malignancy has already been established or is strongly suspected, combining molecular imaging techniques (e.g. ${ }^{18} \mathrm{~F}-\mathrm{FDG}$ PET and ${ }^{68} \mathrm{Ga}$-DOTA PET) takes advantage of the diverse avidities of different tumor types to differentiate lesions of different origins. All the above-mentioned molecular imaging studies should always be reviewed and interpreted in a multidisciplinary (tumor board) meeting in combination with the conventional crosssectional imaging, as the latter remains the imaging of choice for the evaluation of treatment response and disease follow-up.

(c) 2014 S. Karger AG, Base

\section{KARGER}

E-Mail karger@karger.com

www.karger.com/nen (c) 2014 S. Karger AG, Basel

0028-3835/14/0992-0063\$39.50/0
Christos Toumpanakis

Neuroendocrine Tumor Unit, Royal Free Hospital

Pond Street, London NW3 2QG (UK)

E-Mail c.toumpanakis@ucl.ac.uk 


\section{Introduction}

Neuroendocrine tumors (NET) represent a very heterogeneous group of neoplasms despite having a shared origin from neuroendocrine cells. Although they are characterized by relatively slow tumor growth, they have malignant potential and, in fact, many of them are diagnosed only after distant metastases have developed. The primary tumor is most commonly located in the gastrointestinal (GI) tract or the pancreas, in which case the tumors are collectively referred to as gastroenteropancreatic (GEP)-NET. These tumors comprise approximately $2 \%$ of all malignancies of the GEP system [1]. GEP-NET can be functioning, in which case they are associated with a clinical syndrome caused by hormone release and are named according to the hormone they secrete, or nonfunctioning, in which case they have all the histological features of NET but are not associated with a specific clinical syndrome related to hormone hypersecretion.

A common feature of most GEP-NET is their high expression of somatostatin receptors, which has proven to be very important for their management. Five different, G-protein-coupled somatostatin receptor subtypes (SSTR-1 to -5) have been cloned and pharmacologically characterized. Among these receptors, SSTR-2 is expressed in approximately $90 \%$ of GI-NET and in almost $80 \%$ of pancreatic NET (pNET). Exceptions are the insulin-producing pNET (known as insulinomas), in which $<50 \%$ express SSTR-2. Other SSTRs are also expressed in GEP-NET, but to a much lesser extent [2].

According to the recently revised histopathological classification of the World Health Organization (WHO), the following groups of GEP-NET have been recognised: (1) well-differentiated NET and (2) poorly differentiated neuroendocrine carcinomas (NEC). The latter group has aggressive behavior, similar to common cancers. Also, on the basis of mitotic count and the Ki67 proliferation index, well-differentiated GEP-NET are graded either as G1 (with a mitotic count $<2 / 10$ high-power fields and/or Ki67 <2\%) or G2 (with a mitotic count 2-20/10 highpower fields and/or Ki67 2-20\%). All poorly differentiated NEC are G3 (with a mitotic count $>20 / 10$ high-power fields and/or Ki67 >20\%) [3].

The diagnosis of GEP-NET is based upon: (1) clinical features, especially in functioning tumors, (2) levels, in blood and urine, of several peptides and amines produced by the tumor (biomarkers), (3) localization of the primary and/or metastatic lesions as determined by imaging studies, and (4) histopathologic confirmation from biopsy or surgical specimen, which represents the 'gold stan- dard' for diagnosis and should be obtained whenever possible [4].

Many different imaging techniques are used to localize GEP-NET. Cross-sectional (anatomical) imaging modalities, such as ultrasound, computed tomography (CT), and magnetic resonance imaging (MRI) have been used to localize primary lesions and to stage the extent of the disease. In addition, endoscopic techniques, such as endoscopic ultrasound, have been used with great success to identify lesions that may otherwise have been missed on imaging modalities [5].

Molecular (functional) imaging studies, which are based on NET pathophysiology and especially the presence of SSTR-2 and SSTR-5, have proven superior to standard anatomic imaging in terms of more accurate disease staging and selection of eligible patients for certain treatments. Somatostatin receptor scintigraphy (SRS) is the most established functional imaging for NET worldwide, although its value may be limited by several factors, such as its relatively low resolution for small tumors and background binding in normal tissues. It seems that those limitations have been overcome recently by the introduction of newer analogs and chelators [such as DOTA-[Tyr3]-octreotide (TOC)] suitable as tracers for positron emission tomography (PET) imaging. Also, traditional PET scanning using fluorine-18-fluorodeoxyglucose PET $\left({ }^{18} \mathrm{~F}-\mathrm{FDG}\right.$ PET) could be useful in NET with higher Ki67 [6]. Many studies are investigating whether those new imaging modalities alone or in combination are able to provide more precise information about disease extent, patients' response to treatment, and disease course, taking into account the heterogeneity of NET.

In this review, we summarize the available molecular imaging studies and present data for newer techniques of imaging GEP-NET. We also report on the current use of molecular imaging in NET centers globally, evaluating data gathered by questionnaire. Finally, we recommend the techniques most appropriate in specific clinical scenarios.

\section{Methods}

An electronic literature search of the PubMed database was performed using the following search terms: 'somatostatin receptor scintigraphy' (Title/Abstract), 'OctreoScan' (Title/Abstract), '123I MIBG' (Title/Abstract), 'PET scan' (Title/Abstract), 'FDGPET' (Title/Abstract), ' ${ }^{68}$ Gallium-PET' (Title/Abstract), 'neuroendocrine tumor' (Title/Abstract), and 'carcinoid' (Title/Abstract). Only full articles published in peer-reviewed journals and in English were included.

A Web-based survey was constructed comprising of 14 questions with multiple choice answers, gathering information on: (1)
Toumpanakis/Kim/Rinke/Bergestuen/ Thirlwell/Khan/Salazar/Oberg 
Table 1. Oxford Centre for Evidence-Based Medicine: levels of evidence and grades of recommendation

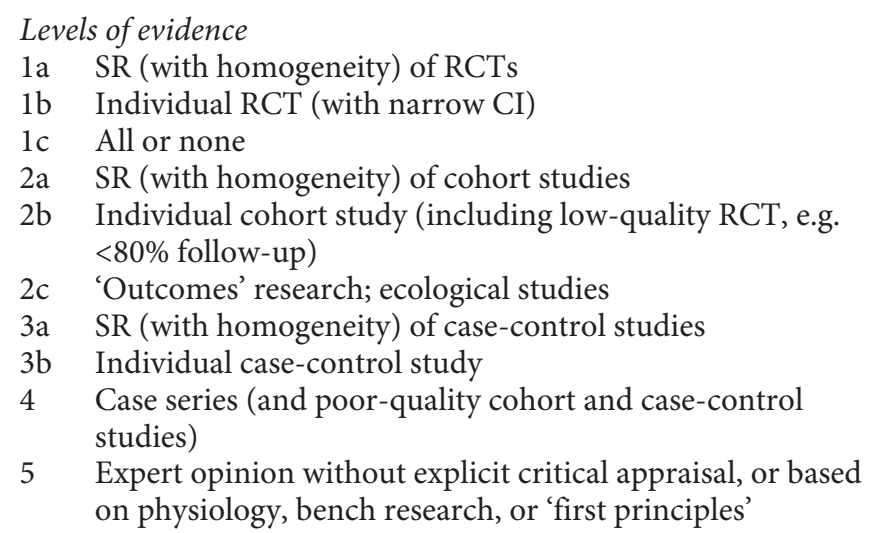

Grades of recommendation

A Consistent level 1 studies

B Consistent level 2 or 3 studies or extrapolations from level 1 studies

C Level 4 studies or extrapolations from level 2 or 3 studies

D Level 5 evidence or troublingly inconsistent or inconclusive studies of any level

$\mathrm{SR}=$ Systemic review; RCT $=$ randomized control trial.

the local availability of biomarkers and molecular imaging studies, (2) the choice of appropriate diagnostic modalities for different types of NET, and (3) intervals for follow-up assessments. It was administered via e-mail to representatives from 103 specialist NET centers around the world over a 6-week period (response rate of $69 \%)$.

The Oxford Centre for Evidence-Based Medicine's levels of evidence (May 2001; table 1) were used to evaluate the evidence for (1) our recommendations for specific clinical scenarios and (2) our proposed algorithm [7].

\section{Overview of Available Molecular Imaging Techniques}

\section{Somatostatin Receptor Scintigraphy}

SRS has been a bulwark in the diagnosis of NET since the 1990s. SRS is based on the affinity of radiolabeled somatostatin analogs for SSTR. The most commonly used tracer is indium-111 ( $\left.{ }^{111} \mathrm{In}\right)$-diethylenetriaminepentaacetic acid (DTPA)-octreotide, also known as ${ }^{111}$ In-pentetreotide, which binds specifically to SSTR-2. The tracer has a half-life of $68 \mathrm{~h}$, allowing for imaging at 24 and $48 \mathrm{~h}$. Currently, SRS remains the first-choice imaging modality for the localization of primary tumors and metastases from GEP-NET. It can also be used to predict responses to treatment with somatostatin analogs and to select patients for peptide receptor radionuclide treatment (PRRT) [8].

The overall sensitivity of SRS for NET is reported to be $89 \%$. The technique is particularly useful for the detection of small intestinal NET, for which the reported sensitivity is $86-95 \%$ [6]. The overall sensitivity for pNET ranges from 60 to 90\% [9]. Combining SRS and single-photon emission CT (SPECT) to give fusion images allows function to be correlated with anatomic location [8]. The sensitivity of SRS is lower in (1) lesions $<1 \mathrm{~cm}$, as they are beyond its resolution [10], (2) insulinomas (estimated sensitivity $<50 \%$ ), likely due to the reduced expression of SSTR-2 in these pNET [6], and (3) well-differentiated NET with a proliferation index $(\mathrm{Ki} 67)>10 \%$ [11]. SRS sensitivity is particularly limited in poorly differentiated NEC [11].

Other somatostatin analogs with different affinities for SSTR are under investigation. These include technetium (Tc)-labeled compounds, which cost less, are more readily available, and allow faster tumor visualization (with a maximum uptake at $1 \mathrm{~h}$ after infusion) compared with In-labeled compounds [8]. The ${ }^{99 \mathrm{~m}} \mathrm{Tc}$-labeled somatostatin analogs researched to date include ${ }^{99 \mathrm{~m}} \mathrm{Tc}$-depreotide, which binds to SSTR-2, -3 , and -5 with high affinity $[12,13]$, and ${ }^{99 \mathrm{~m}} \mathrm{Tc}$-vapreotide, which binds to SSTR-2 and -5 with high affinity, and to SSTR-3 and -4 with moderate affinity [8]. ${ }^{99 \mathrm{~m}}$ Tc-6-hydrazinopyridine-3-carboxylic acid (HYNIC)TOC and ${ }^{99 m}$ Tc-HYNIC-[Tyr3, Thr8]-octreotide (TATE) have been used to image GEP-NET, with similar success to ${ }^{111}$ In-pentetreotide in the localization of somatostatin-expressing tumors [14-16]. Iodine-123 $\left({ }^{123} \mathrm{I}\right)$-labeled vasoactive intestinal peptide has also been evaluated; however, this tracer, which binds SSTR-3, has shown lower sensitivity than ${ }^{111}$ In-pentetreotide for gastrinomas and glucagonomas [8].

${ }^{123}$ I-Metaiodobenzyl-Guanidine Scintigraphy

${ }^{123}$ I-metaiodobenzyl-guanidine (MIBG) is an analog of guanethidine, which is taken up by the cell membranes of sympathomedullary tissues and then further stored in catecholamine storage vesicles. ${ }^{123} \mathrm{I}-\mathrm{MIBG}$ scintigraphy is the first choice for imaging of functional pheochromocytomas, paragangliomas, and neuroblastomas [8]. However, ${ }^{123}$ I-MIBG scintigraphy is not routinely recommended in the diagnostic workup of patients with GEPNET because it has a much lower sensitivity than SRS in the imaging of small-bowel NETs (52 vs. $89 \%$, respectively), and its sensitivity in pNET is only 9\% [17]. A complementary role is appropriate, however, to assess the feasibility of treatment with ${ }^{131} \mathrm{I}-\mathrm{MIBG}$. 


\section{Positron Emission Tomography}

PET represents an excellent clinical tool in oncology with its generally high sensitivity and resolution. PET allows for whole-body scanning and quantification of tracer uptake. It provides metabolic images based on metabolic variations between normal and malignant cells.

\section{${ }^{18}$ F-FDG PET}

${ }^{18}$ F-FDG PET is extremely important in general oncologic imaging, as it detects the increased glucose metabolism of cancer cells. Although ${ }^{18}$ F-FDG PET has not been as useful for the imaging of well-differentiated GEP-NET with low proliferation indices, it does play an important role in more aggressive tumors [8]. Binderup et al. [9] have shown that ${ }^{18} \mathrm{~F}$-FDG PET has a sensitivity of $92 \%$ for the detection of NET with a proliferation index of $>15 \%$, compared with $69 \%$ for SRS. Also, in a series of 18 NET patients with Ki-67 $>10 \%,{ }^{18}$ F-FDG PET detected more, the same as, and fewer tumor lesions than SRS in 78,6 , and $17 \%$ of patients, respectively [11]. The role of ${ }^{18} \mathrm{~F}-\mathrm{FDG}$ PET for predicting treatment response was highlighted in a recent study which included G1 or G2 advanced NET, as none of the ${ }^{18} \mathrm{~F}$-FDG PET-negative patients had progressed at the first follow-up examination after ${ }^{177} \mathrm{Lu}-\mathrm{DOTA}-\mathrm{TATE}$ PRRT. In that study population, G2 NET and ${ }^{18} \mathrm{~F}-\mathrm{FDG}$ PET positivity were frequently associated with more aggressive disease course [18]. Finally, it seems that avid uptake in ${ }^{18} \mathrm{~F}$-FDG PET predicts survival. In a prospective study enrolling 98 NET patients, univariate analysis showed that a ${ }^{18}$ F-FDG PET maximal standardized uptake value $\left(\mathrm{SUV}_{\max }\right)$ of $>9$ and a high Ki67 index were significant predictors of overall survival, with hazard ratios (HR) of 8.8 (95\% CI: 2.7-28.7) and 2.6 (95\% CI: 1.3-5.1), respectively. In a multivariate analysis including $\mathrm{SUV}_{\max }>3$, $\mathrm{Ki}-67$, and chromogranin $\mathrm{A}$, only $\mathrm{SUV}_{\max }>3$ was a predictor of progression-free survival $(\mathrm{HR}=8.4 ; \mathrm{p}<0.001)$ [19].

\section{Carbon-11-5-Hydroxy-L-Tryptophan PET and}

${ }^{18} \mathrm{~F}$-Dihydroxyphenylalanine PET

The knowledge that NET take up and decarboxylate amine precursors has led to the development of carbon-11 $\left({ }^{11} \mathrm{C}\right)$-5-hydroxy-L-tryptophan (5-HTP) PET and ${ }^{18} \mathrm{~F}$-dihydroxyphenylalanine (DOPA) PET $[10,20] .{ }^{11} \mathrm{C}$ 5-HTP PET is more effective in the detection of NET than both CT and SRS, and may be particularly useful in detecting small tumors and early recurrences. On the other hand, ${ }^{18} \mathrm{~F}$-DOPA PET performs better than SRS in carcinoids, but not in noncarcinoid NET [10]. One study compared ${ }^{11} \mathrm{C}-5$-HTP PET and ${ }^{18} \mathrm{~F}$-DOPA PET in patients with GI-NET and pNET. For GI-NET, ${ }^{18} \mathrm{~F}$-DOPA PET was found to be more sensitive than ${ }^{11} \mathrm{C}$-5-HTP PET (98 vs. $89 \%$, respectively), while the opposite was noted for patients with pNET (80 vs. 96\%, respectively) [21]. A limitation of ${ }^{11} \mathrm{C}-5 \mathrm{HTP}$ PET is the need for a cyclotron to produce the required isotope [10]. Thus, this technique is available in only a few centers worldwide.

Gallium-68 ( $\left.{ }^{68} \mathrm{Ga}\right)-1,4,7,10$

Tetraazacyclododecane, $1,4,7,10$

DOTA-Conjugated Peptides PET

Imaging with ${ }^{68} \mathrm{Ga}$-labeled somatostatin analogs provides some advantages over SRS imaging, and has therefore recently become more popular. ${ }^{68} \mathrm{Ga}$ has a short halflife of $68 \mathrm{~min}$, allowing imaging after only $1 \mathrm{~h}$ and completion within $2-3 \mathrm{~h}$, in contrast to the $24-48 \mathrm{~h}$ required for SRS [10]. With a higher affinity for NET than ${ }^{111}$ Inpentetreotide, ${ }^{68} \mathrm{G}$ a is a generator-produced positron that does not need a cyclotron. Moreover, ${ }^{68} \mathrm{Ga}$ gives better spatial resolution than SRS-SPECT [9]. Finally, the effective dose is less than half of the dose provided by ${ }^{111} \mathrm{In}$ DTPA-OCT [22].

Multiple peptides have been used with in conjunction with ${ }^{68} \mathrm{Ga}$. Somatostatin analogs such as DOTA-TOC, DOTA-TATE, and DOTA-[Nal3]-octreotide (NOC) have recently been used with PET imaging. They demonstrate differing affinity profiles for the SSTR subtypes: ${ }^{68} \mathrm{Ga}$ DOTA-TATE has high affinity for SSTR-2, ${ }^{68} \mathrm{Ga}$ DOTA-TOC for SSTR-2 and -5 , and ${ }^{68} \mathrm{Ga}$ DOTA-NOC for SSTR-2, -3, and -5 [23].

According to the results of a recent meta-analysis that included 16 studies, the pooled sensitivity and specificity of ${ }^{68} \mathrm{Ga}$-DOTA PET were 93 and $91 \%$, respectively [24]. False-negative results are mainly associated with very small lesions $(<7 \mathrm{~mm})$, which are beyond the resolution of PET, and with tumors with low SSTR expression, such as poorly differentiated NEC and insulinomas. However, two key facts need to be taken into account when interpreting these imaging studies: (1) inflammatory diseases can be associated with false-positive results and (2) ${ }^{68} \mathrm{Ga}$ DOTA PET uptake in the uncinate process of the pancreas, the adrenal gland, and accessory spleens can be physiologic $[25,26]$.

In recent years, ${ }^{68} \mathrm{Ga}$-DOTA PET studies have not only aided in the diagnosis and localization of tumors but also in determining the most appropriate management of NET [27-29]. Hofman et al. [27] investigated the impact of ${ }^{68} \mathrm{Ga}$-DOTA-TATE compared with ${ }^{111}$ In-octreotide in the management of a series of 59 NET patients. The impact was high, leading to a change in modality (e.g. from surgery to chemotherapy) in $47 \%$ of patients.
Toumpanakis/Kim/Rinke/Bergestuen/ Thirlwell/Khan/Salazar/Oberg 
${ }^{68} \mathrm{Ga}$-DOTA-TATE PET (fig. 1) seems to be superior to ${ }^{18} \mathrm{~F}$-FDG PET in the detection of G1- and G2-grade NET, with median SUV $V_{\max }$ values for ${ }^{68} \mathrm{Ga}$-DOTA-TATE PET of 29 and 15.5, respectively, compared with values for ${ }^{18} \mathrm{~F}$-FDG PET of 2.9 and 10.5. In contrast, there is a much higher uptake of ${ }^{18} \mathrm{~F}$-FDG than ${ }^{68} \mathrm{Ga}$-DOTA-TATE in high-grade (G3) NET (SUV max $_{\text {ax }}$ of 1.7 for FDG vs. 4.4 for DOTA-TATE) [26]. Only one small study has compared ${ }^{68} \mathrm{Ga}$-DOTA-NOC with ${ }^{18} \mathrm{~F}$-DOPA directly; in this study, ${ }^{68} \mathrm{Ga}$-DOTA-NOC revealed more lesions and more occult primary tumors [27]. Compared with CT, ${ }^{68} \mathrm{Ga}$ DOTA-NOC PET has demonstrated a higher sensitivity ( 80 vs. $100 \%$, respectively) and specificity (98 vs. $100 \%$ ) in the detection of NET bone metastases [30]. Finally, Kabasakal et al. [31] compared ${ }^{68} \mathrm{Ga}$-DOTA-TATE and ${ }^{68} \mathrm{Ga}$-DOTA-NOC in the same NET patient group. Both tracers demonstrated physiologic uptake in SSTR-2-expressing organs (e.g. pituitary, salivary, thyroid, and prostate glands), but the physiologic uptake in pituitary and salivary glands was much higher for ${ }^{68} \mathrm{Ga}$-DOTA-TATE than ${ }^{68} \mathrm{Ga}$-DOTA-NOC. Although the tracers seem to have similar diagnostic accuracy, ${ }^{68} \mathrm{Ga}$-DOTA-TATE seems to provide a significantly higher lesion uptake than ${ }^{68}$ Ga-DOTA-NOC [31].

\section{Novel Imaging Techniques}

A number of new agents are currently under investigation. In a study by Gotthardt et al. [32], for example, positive gastrin receptor scintigraphy results were obtained in GEP-NET patients with negative ${ }^{111}$ In-labeled SRS. One preclinical study assessed ${ }^{68} \mathrm{Ga}$-DOTA-minigastrin (MG0) for the detection of cholecystokinin-2 (CCK2)/gastrin receptor-positive tumors in a murine model [33]. This study took advantage of the binding of radiolabeled minigastrin to the CCK2/gastrin receptor, which is expressed on the majority of NET and medullary thyroid carcinomas. High receptor affinity was demonstrated with ${ }^{68} \mathrm{Ga}$-DOTA-MG0, with appropriate blockade upon administration of competing peptides. Tumors expressing the CCK2/gastrin receptor were then visualized with small-animal PET imaging. This study demonstrates that ${ }^{68} \mathrm{Ga}-\mathrm{DOTA}-\mathrm{MG} 0$ is a promising tracer for use with PET imaging in humans with CCK2/gastrin receptor-positive tumors [33]. Based on the fact that glucagon-like peptide-1 (GLP-1) receptors are expressed in high density in almost all benign insulinomas, Wild et al. [34] demonstrated for the first time the superiority of GLP-1 receptor SPECT/CT scans, using ${ }^{111}$ In-labeled [Lys ${ }^{40}(\mathrm{Ahx}-\mathrm{DTPA}) \mathrm{NH}_{2}$ ]-exendin-4 as a tracer. The same group of authors confirmed those en-

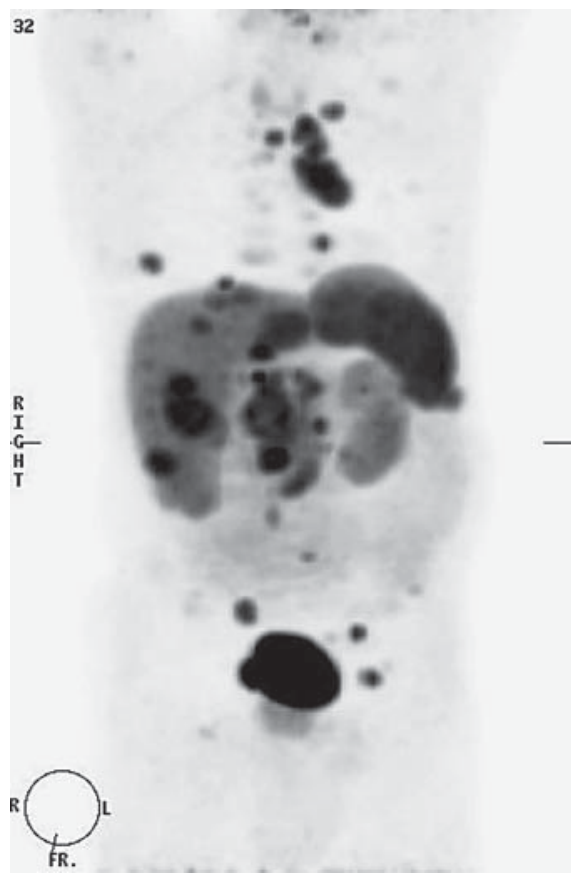

Fig. 1. ${ }^{68} \mathrm{Ga}$-DOTA-TATE PET scan of a patient with a metastatic pNET, demonstrating the pancreatic primary tumor, multiple hepatic, lung, and bone metastases, and intra-abdominal and mediastinal lymphadenopathy.

couraging results, using the same ${ }^{111}$ In-labelled GLP-1 receptor agonist, in 6 patients with benign insulinomas [35]. On the contrary, they showed that GLP-1 imaging has limited sensitivity in malignant insulinomas, where SSTR-2 receptor imaging studies seem to be superior [36]. Recently, Sowa-Staszczak et al. [37] demonstrated $100 \%$ sensitivity and specificity in similar patients, with [Lys ${ }^{40}$ (Ahx-HYNIC- ${ }^{99 m}$ Tc/EDDA) $\mathrm{NH}_{2}$ ] -exendin- 4 . The authors of this study suggest that the GLP-1 receptor tracer labelled with ${ }^{99 \mathrm{~m}} \mathrm{Tc}$ instead of ${ }^{111} \mathrm{In}$ is characterized by the general availability of the isotope, lower radiation exposure to patients and staff, and potential usefulness of this compound for intraoperative localization of insulinoma foci using a gamma probe. Finally, this promising diagnostic method seems to have some therapeutic implications as well. Wicki et al. [38] treated a transgenic mouse model of human insulinoma using $\left[\right.$ Lys $^{40}\left(\right.$ Ahx-DTPA- ${ }^{111}$ In $) \mathrm{NH}_{2}$ ]-exendin-4. No significant acute organ toxicity was noted, while the tumor volume decreased up to $94 \%$.

The sensitivity of all available molecular imaging techniques in well-differentiated G1 and G2 NET is summarized in table $2[6,9,17,21,24]$. 
Table 2. Sensitivity of molecular imaging modalities in well-differentiated G1 and G2 GEP-NET

Sensitivity, \%

\begin{tabular}{ll}
\hline SRS & \\
Overall & 89 \\
Intestinal NET & $80-95$ \\
pNET & $60-90$ \\
${ }^{123}$ I-MIBG & \\
Overall & 76 \\
Intestinal NET & 52 \\
pNET & 9 \\
${ }^{18}$ F-FDG PET & \\
Overall & 84 \\
NET with Ki67 <15\% & 53 \\
NET with Ki67 >15\% & 92 \\
${ }^{68}$ Ga (DOTA)-conjugated peptides PET & \\
Overall & $82-100$ \\
${ }^{11}$ C-5-HTP PET & \\
Overall & $89-96$ \\
Intestinal NET & 89 \\
pNET & 96 \\
${ }^{18}$ F-DOPA PET & \\
Overall & $80-98$ \\
Intestinal NET & 98 \\
pNET & 80 \\
\hline
\end{tabular}

\section{Results of the International Survey}

In total, completed questionnaires were received from 72 centers. The majority of participating NET centers were European (68\%), with the others located in the USA, South America, and Israel. Due to the large number of responses from Spanish centers (26 centers) compared to the rest of Europe ( 23 centers), each survey item was analyzed for differences between these two subgroup responses using $\chi^{2}$ or Fisher's exact test with Bonferroni correction. There were no significant differences in responses. $47 \%$ of the centers had $>500$ patients under their care, while $71 \%$ of the Spanish centers had $<100$ patients under their care compared to $22 \%$ in the rest of Europe. Based on the previously noted statistical methods, no significant differences in responses between centers with $>500$ patients versus centers with $<500$ patients were noted.

Most NET centers have access to SRS and ${ }^{18}$ F-FGDPET while, as expected, only a small number of NET centers $(<20 \%)$ have access to ${ }^{18} \mathrm{~F}$-DOPA PET or ${ }^{68} \mathrm{Ga}$ PET. Although the majority of centers $(84 \%)$ would include SRS in their initial diagnostic workup, almost $10 \%$ would never perform an SRS at the time of diagnosis. The latter centers have regular access to ${ }^{68} \mathrm{Ga}$-DOTA PET and it seems that they prefer this novel imaging modality to SRS. On the contrary, the vast majority of NET centers (89\%) that participated in the survey stated that, even if they had all of the molecular imaging techniques available, they would use ${ }^{123} \mathrm{I}-\mathrm{MIBG},{ }^{18} \mathrm{~F}$-DOPA PET, and ${ }^{68} \mathrm{Ga}$-DOTA PET only in selected patients. However, almost $10 \%$ of NET centers would routinely perform ${ }^{18} \mathrm{~F}-\mathrm{FDG}$ PET at the time of diagnosis.

Finally, the majority of NET centers (52\%) would perform molecular imaging routinely during follow-up.

\section{Recommendations for Specific Clinical Scenarios}

\section{Assessment of Patients with Well-Differentiated GEP-NET}

SRS can still be considered the molecular imaging technique of choice at diagnosis and follow-up in the majority of patients with well-differentiated GEP-NET (level of evidence 3 , grade of recommendation A/B). In patients with negative SRS or equivocal findings, however, ${ }^{68} \mathrm{Ga}$-DOTA-TATE PET, if available, is recommended, as it can identify additional lesions and may therefore influence the way the disease is managed (level of evidence 3, grade of recommendation B) [39]. Although results from a small study discussed previously suggest ${ }^{18}$ F-FDG PET can be superior to SRS in well-differentiated NET with Ki67 $>10 \%$ [11], the routine use of ${ }^{18}$ F-FDG PET in these patients cannot be definitely recommended, as more research is needed. However, if ${ }^{18} \mathrm{~F}-\mathrm{FDG}$ PET is performed for some reason in well-differentiated NET and is positive, this may indicate a more aggressive disease course. Also, if FDG-PET and SRS have demonstrated uptake in different tumor lesions in the same patient, a heterogeneous NET cell population can be suspected and a repeat biopsy may be considered (level of evidence 5, grade of recommendation $\mathrm{D}$ ). The routine use of ${ }^{123}$ I-MIBG scintigraphy cannot be recommended, as it is positive in only $9 \%$ of pNET and approximately $50 \%$ of small-bowel NET. However, it can be requested in advanced small-bowel NET, when patients are considered as candidates for ${ }^{131} \mathrm{I}$ MIBG treatment (level of evidence 3, grade of recommendation $\mathrm{C})$.

Assessment of Patients with Poorly Differentiated NEC

${ }^{18} \mathrm{~F}-\mathrm{FDG}$ PET can be considered the first-choice molecular imaging technique in poorly differentiated NEC because SRS is often negative and ${ }^{68} \mathrm{Ga}$-DOTA PET shows only low-grade uptake (level of evidence 3 , grade of rec-
68

Neuroendocrinology 2014;99:63-74 DOI: $10.1159 / 000358727$
Toumpanakis/Kim/Rinke/Bergestuen/ Thirlwell/Khan/Salazar/Oberg 
ommendation $\mathrm{A} / \mathrm{B}$ ) [8]. In those types of tumors, ${ }^{18} \mathrm{~F}$ FDG PET can reveal unsuspected tumor lesions, leading clinicians to revise disease management plans, particularly with regards to interventional treatments. However, in poorly differentiated NEC with progressing disease, despite systemic chemotherapy (which is the initial treatment of choice in these patients), and as alternative treatment options are very limited, it is not unreasonable to request an SRS or ${ }^{68} \mathrm{Ga}$-labeled PET (level of evidence 5, grade of recommendation D). In the unlikely scenario that these scans show good tracer uptake, the patient may be a candidate for PRRT. There are no accurate factors so far that could predict a positive uptake in SRS or ${ }^{68} \mathrm{Ga}$ labeled PET in those tumors.

\section{Assessment of Patients with NET of Unknown}

Primary Location and Patients with Suspected NET

It is not uncommon for NET to present late in the disease course with evidence of extensive hepatic metastases revealed by conventional cross-sectional imaging (i.e. CT and MRI), but in which the primary tumor cannot be clearly identified. Detection of the primary tumor site is important to optimize the treatment strategy, given that response rates to several treatment options differ for metastatic small-bowel NET and pNET. Although immunohistochemistry in the biopsy specimen from a metastatic lesion could be quite helpful (e.g. serotonin expression most likely indicates a small-bowel primary), the combination of cross-sectional imaging with molecular imaging is equally important towards that direction, as it may also provide information about the anatomic location of the primary lesion. As the sensitivity of SRS is only $39 \%$ in patients with advanced NET of unknown primary location [40], new molecular imaging techniques are warranted in this setting. The location of the primary tumor can be visualized with ${ }^{68} \mathrm{Ga}$-DOTA-NOC PET in $60 \%$ of cases, resulting in amendments to the management plan in $10-15 \%$ of patients (level of evidence 3 , grade of recommendation $\mathrm{A} / \mathrm{B}$ ) [41]. As malignant insulinomas often express SSTR-2, unlike their benign counterparts, they can also be revealed with ${ }^{68} \mathrm{Ga}$ DOTA-TATE PET [36]. For solitary benign insulinomas, GLP-1 receptor imaging represents an important emerging diagnostic tool (level of evidence 4, grade of recommendation C) [35]. In patients in whom clinical, biochemical, or radiologic findings raise the suspicion of an NET, ${ }^{68} \mathrm{Ga}$-DOTA-peptide PET should be used with caution. According to a recent study, ${ }^{68} \mathrm{Ga}$-DOTA-NOC PET gave true positives in approximately $13 \%$ of cases with suspicious lesions in conventional imaging, in $10 \%$ of cases with relevant symptoms/signs, and in only $1.5 \%$ of cases for whom an NET was suspected based on abnormal biomarkers [42].

\section{Patients with Documented/Suspected Secondary Malignancies}

According to recent epidemiologic data, approximately $22 \%$ of patients with NET develop other malignancies [43]. Such secondary malignancies are more likely when the primary NET is in the small bowel, and they are more likely to occur synchronously than metachronously. The suspicion for a second malignancy is usually raised on follow-up cross-sectional imaging (CT/MRI) either because the new lesion(s) have non-NET radiological appearances or have an unusually rapid rate of progression for NET (level of evidence 5, grade of recommendation C). Concomitant use of ${ }^{18}$ F-FDG PET and more specific molecular imaging for well-differentiated NETs, such as ${ }^{68} \mathrm{Ga}$-DOTA-TATE, may facilitate the identification of the origin of metastatic lesions (level of evidence 4, grade of recommendation C; fig. 2). Indeed, Desai et al. [44] reported an interesting case in which molecular imaging was used to differentiate hepatic metastases originating from colorectal cancer and hepatic metastases originating from an NET in the same patient. An ${ }^{18}$ F-FDG PET is therefore recommended for NET patients who develop new indeterminate tumor lesions with cross-sectional imaging whenever there is a past medical history of a second malignancy or when a second primary is suspected (level of evidence 4, grade of recommendation C). In such cases, ${ }^{18} \mathrm{~F}$-FDG PET should be compared with either SRS or ${ }^{68} \mathrm{Ga}$-DOTA PET, as well as with patient's cross-sectional imaging in the multidisciplinary team meeting, and if necessary a biopsy of the new suspicion lesion may be arranged (level of evidence 5, grade of recommendation D).

\section{Molecular Imaging before and after PRRT}

Patients who are considered candidates for PRRT should first undergo SRS to confirm avid tracer uptake by the tumor lesions (level of evidence 3, grade of recommendation A/B). In cases of well-differentiated NET with negative SRS, ${ }^{68} \mathrm{Ga}$-DOTA PET should still be performed, as it may independently demonstrate good uptake. ${ }^{68} \mathrm{Ga}$ DOTA PET is also valuable in the evaluation of receptor status before PRRT, as it can determine the receptor density semiquantitatively by the measurement of SUV (level of evidence 3, grade of recommendation $\mathrm{C}$ ). In the study noted earlier [39], ${ }^{68} \mathrm{Ga}$-DOTA-TATE PET was positive in $74 \%$ of tumor lesions for which SRS was nega- 


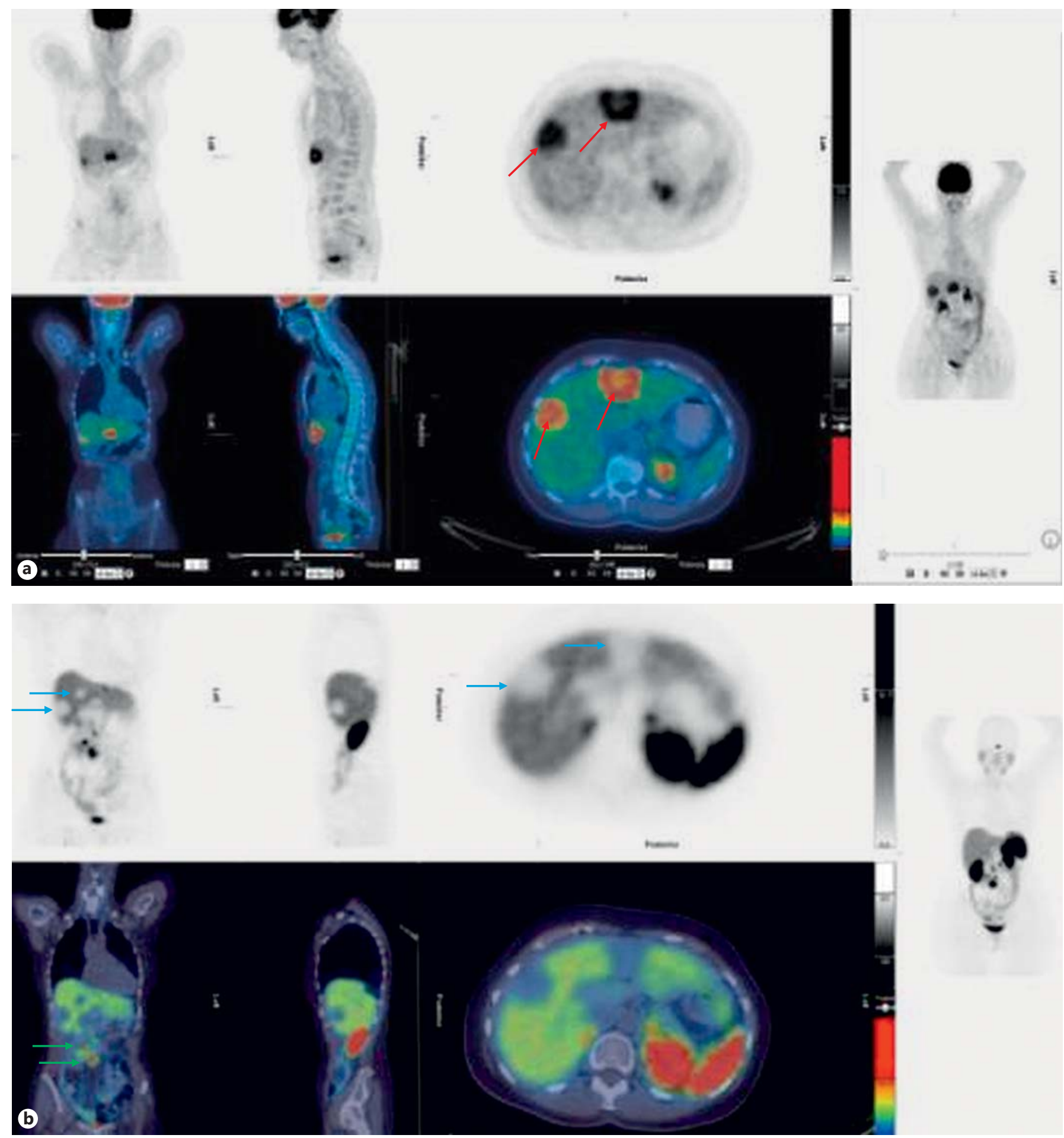

Fig. 2. ${ }^{18}$ F-FDG PET and ${ }^{68}$ Ga-DOTA-TATE PET in a patient with a history of Meckel's diverticulum NET and colorectal cancer. a ${ }^{18}$ F-FDG PET showing avid uptake in 2 colorectal cancer metastases (confirmed histopathologically, posthepatectomy, red ar- rows). $\mathbf{b}^{68} \mathrm{Ga}$ DOTA-TATE PET of the same patient showing avid uptake in Meckel's diverticulum NET, mesenteric node and with segment 2 NET liver metastasis (green arrows), but no uptake in colorectal liver metastases which appear photopenic (blue arrows). 


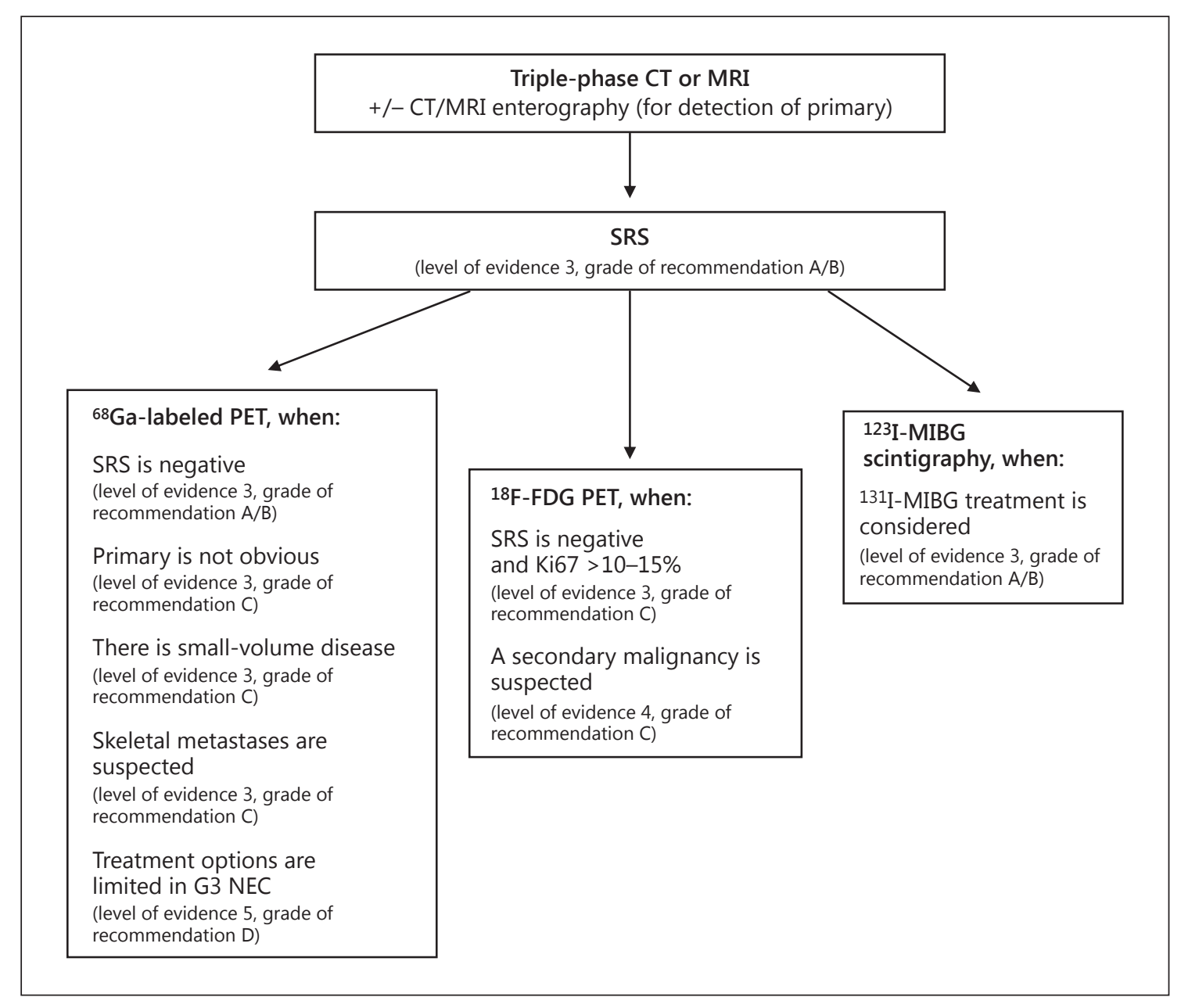

Fig. 3. Imaging algorithm for intestinal NET.

tive or equivocal; consequently, 39\% of patients were considered suitable for PRRT. Treatment responses did not differ between patients for whom ${ }^{68} \mathrm{Ga}$-DOTA-TATE PET was positive but SRS negative and patients who had PRRT following a positive SRS. As tumor responses following PRRT should always be evaluated with cross-sectional imaging following completion of treatment course, there are no clear recommendations regarding the routine use of either SRS or ${ }^{68} \mathrm{Ga}$-DOTA PET for this purpose. However, there are some preliminary data suggesting that $\mathrm{SUV}_{\max }$ can be used to discriminate between a partial response and stable disease (level of evidence 4, grade of recommendation C) [26].

On the basis of the above, proposed imaging algorithms for advanced intestinal and pNET (also including benign insulinoma, as an exception) are presented in figures 3 and 4 , respectively.

\section{Conclusions}

SRS continues to have a central role in the diagnostic workup of patients with GEP-NET. It is available in the majority of NET centers worldwide, and almost all NET specialists request SRS as part of the initial assessment of patients. However, its limited sensitivity in small tumor lesions, insulinomas, and poorly differentiated NEC needs to be taken into account.

${ }^{18}$ F-FDG PET is particularly helpful for visualizing more aggressive NET, such as poorly differentiated NEC, and well-differentiated tumors with Ki67 values $>10 \%$. Limited data so far have shown that ${ }^{18} \mathrm{~F}-\mathrm{FDG}$-avid tumor lesions, even in slow-growing NET, may indicate a more aggressive disease course.

${ }^{68} \mathrm{Ga}$-DOTA PET represents a recent development in NET molecular imaging, which may replace SRS in the 


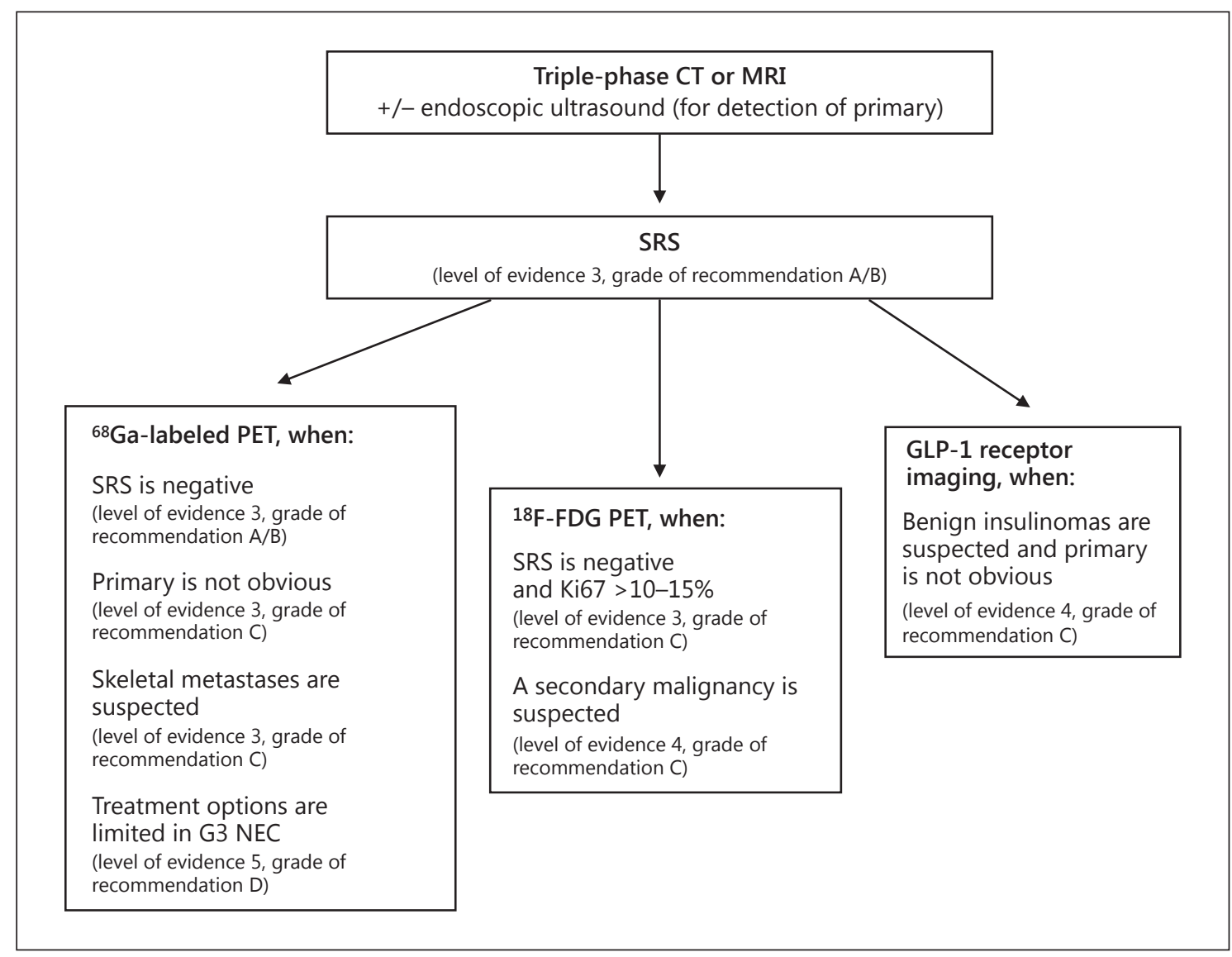

Fig. 4. Imaging algorithm for $\mathrm{pNET}$.

future, as it has technical advantages over SRS in terms of image quality and patient convenience, and has better sensitivity in patients with small-volume disease, in patients with skeletal metastases, and in those with occult primary tumors. To date, however, there are no prospective randomized studies comparing the two imaging modalities in the same patient population, and ${ }^{68} \mathrm{Ga}$-DOTA PET is not widely available.

GLP-1 receptor imaging represents a very promising diagnostic tool for localization of the primary in benign insulinomas; however, it is available only in very limited centers.

${ }^{11} \mathrm{C}-5$-HTP PET and ${ }^{18} \mathrm{~F}-\mathrm{DOPA}$ PET are also new molecular imaging techniques for NET. Their availabilities, however, are even more limited than that of ${ }^{68} \mathrm{Ga}$-DOTA PET and, based on retrospective data, their sensitivities seem to be inferior to that of ${ }^{68} \mathrm{Ga}$-DOTA PET.

Finally, when a secondary malignancy has already been established or is strongly suspected, combining mo- lecular imaging techniques (e.g. FDG PET and ${ }^{68} \mathrm{Ga}$ DOTA PET) takes advantage of the diverse avidities of different tumor types to differentiate lesions of different origins.

All the molecular imaging studies discussed above should always be reviewed and interpreted in a multidisciplinary (tumor board) meeting in combination with the conventional cross-sectional imaging, as the latter remains the imaging of choice for evaluation of treatment response and disease follow-up.

\section{Acknowledgments}

The authors wish to thank the other participants of the Knowledge Network. They would also like to thank the centers that responded to their questionnaire (for a list of the centers that provided their details, see the online supplementary material, www. karger.com/doi/10.1159/000358727). 
This article was developed independently by members of a working group of the Knowledge Network. This program involved meetings and collaboration between clinicians working in the field of NET around the world, which was organized and funded by Ip- sen. Editing assistance was provided by Watermeadow Medical and funded by Ipsen. The authors were fully responsible for the concept and all content, for all editorial decisions, and for approval of the final version.

\section{References}

1 Caplin ME, Buscombe JR, Hilson AJ, Jones AL, Watkinson AF, Burroughs AK: Carcinoid tumour. Lancet 1998;352:799-805.

2 Reubi JC, Laissue J, Waser B, Horisberger U, Schaer JC: Expression of somatostatin receptors in normal, inflammed and neoplastic human gastrointestinal tissues. Ann NY Acad Sci 1994;733:122-137.

3 Rindi G, Arnold R, Bosman FT, et al: Nomenclature and classification of neuroendocrine neoplasms of the digestive system; in Bosman FT, Carneiro F, Hruban RH, Theise ND (eds): WHO Classification of Tumours in the Digestive System, ed 4. Lyon, IARC, 2010, pp 1314.

-4 Plöckinger U, Rindi G, Arnold R, Eriksson B, Krenning EP, de Herder WW, Goede A, Caplin M, Oberg K, Reubi JC, Nilsson O, Delle Fave G, Ruszniewski P, Ahlman H, Wiedenmann B; European Neuroendocrine Tumor Society: Guidelines for the diagnosis and treatment of neuroendocrine gastrointestinal tumors. A consensus statement on behalf of the European Neuroendocrine Tumor Society (ENETS). Neuroendocrinology 2004;80: 394-424.

5 Ramage JK, Davies AH, Ardill J, Bax N, Caplin M, Grossman A, Hawkins R, McNicol AM, Reed N, Sutton R, Thakker R, Aylwin S, Breen D, Britton K, Buchanan K, Corrie P, Gillams A, Lewington V, McCance D, Meeran K, Watkinson A: Guidelines for the management of gastroenteropancreatic neuroendocrine (including carcinoid) tumors. Gut 2005;54 (suppl 4):1-16.

-6 Sundin A, Garske U, Orlefors H: Nuclear imaging of neuroendocrine tumours. Best Pract Res Clin Endocrinol Metab 2007;21:69-85.

7 Centre for Evidence Based Medicine. Levels of Evidence. http://www.cebm. net/index. aspx? ${ }^{1 / 1} / 1025$ (accessed June 2011).

$>8$ de Herder WW, Lamberts SW: Somatostatin and somatostatin analogues: diagnostic and therapeutic uses. Curr Opin Oncol 2002;14: 53-57.

$\checkmark 9$ Binderup T, Knigge U, Loft A, Mortensen J, Pfeifer A, Federspiel B, Hansen CP, Højgaard L, Kjaer A: Functional imaging of neuroendocrine tumors: a head-to-head comparison of somatostatin receptor scintigraphy, ${ }^{123} \mathrm{I}$ MIBG scintigraphy, and ${ }^{18} \mathrm{~F}$-FDG PET. J Nucl Med 2010;51:704-712.

10 Oberg K, Castellano D: Current knowledge on diagnosis and staging of neuroendocrine tumors. Cancer Metastasis Rev 2011;30 (suppl 1):3-7.
11 Abgral R, Leboulleux S, Déandreis D, Aupérin A, Lumbroso J, Dromain C, Duvillard P, Elias D, de Baere T, Guigay J, Ducreux M, Schlumberger M, Baudin E: Performance of (18)fluorodeoxyglucose-positron emission tomography and somatostatin receptor scintigraphy for high Ki67 ( $\geq 10 \%)$ well-differentiated endocrine carcinoma staging. J Clin Endocrinol Metab 2011;96:665-671.

12 Lebtahi R, Le Cloirec J, Houzard C, Daou D, Sobhani I, Sassolas G, Mignon M, Bourguet P, Le Guludec D: Detection of neuroendocrine tumors: 99mTc-P829 scintigraphy compared with ${ }^{111}$ In-pentetreotide scintigraphy. J Nucl Med 2002;43:889-895.

13 Shah T, Kulakiene I, Quigley AM, Warbey VS, Srirajaskanthan R, Toumpanakis C, Hochhauser D, Buscombe J, Caplin ME: The role of ${ }^{99 \mathrm{~m}} \mathrm{Tc}$-depreotide in the management of neuroendocrine tumors. Nucl Med Commun 2008:29:436-440.

14 Decristoforo C, Melendez-Alafort L, Sosabowski JK, Mather SJ: ${ }^{99 \mathrm{~m}}$ Tc-HYNIC-[Tyr3] octreotide for imaging somatostatin-receptor-positive tumors: preclinical evaluation and comparison with ${ }^{111}$ In-octreotide. J Nucl Med 2000;41:1114-1119.

15 Gabriel M, Decristoforo C, Donnemiller E, Ulmer H, Watfah Rychlinski C, Mather SJ, Moncayo R: An intrapatient comparison of ${ }^{99 m}$ Tc-EDDA/HYNIC-TOC with ${ }^{111}$ In-DTPoctreotide for diagnosis of somatostatin receptor-expressing tumors. J Nucl Med 2003; 44:708-716.

16 Cwikla JB, Mikolajczak R, Pawlak D, Buscombe JR, Nasierowska-Guttmejer A, Bator A, Maecke HR, Walecki J: Initial direct comparison of ${ }^{99 \mathrm{~m}} \mathrm{Tc}$-TOC and ${ }^{99 \mathrm{~m}} \mathrm{Tc}$-TATE in identifying sites of disease in patients with proven GEP NETS. J Nucl Med 2008;49: 1060-1065.

17 Kaltsas G, Rockall A, Papadogias D, Reznek $\mathrm{R}$, Grossman AB: Recent advances in radiological and radionuclide imaging and therapy of neuroendocrine tumors. Eur J Endocrinol 2004;151:15-27.

18 Severi S, Nanni O, Bodei L, et al: Role of ${ }^{18} \mathrm{FDG}$ PET/CT in patients treated with ${ }^{177} \mathrm{Lu}-$ DOTATATE for advanced differentiated neuroendocrine tumours. Eur J Nucl Med Mol Imaging 2013;40:881-888.

$\checkmark 19$ Binderup T, Knigge U, Loft A, Federspiel B, Kjaer A: ${ }^{18} \mathrm{~F}$-fluorodeoxyglucose positron emission tomography predicts survival of patients with neuroendocrine tumors. Clin Cancer Res 2010;16:978-985.
20 Orlefors H, Sundin A, Ahlström H, Bjurling $\mathrm{P}$, Bergström M, Lilja A, Långström B, Oberg $\mathrm{K}$, Eriksson B: Positron emission tomography with 5-hydroxytryprophan in neuroendocrine tumors. J Clin Oncol 1998;16:25342541.

21 Koopmans KP, Neels OC, Kema IP, Elsinga $\mathrm{PH}$, Sluiter WJ, Vanghillewe K, Brouwers AH, Jager PL, de Vries EG: Improved staging of patients with carcinoid and islet cell tumors with ${ }^{18} \mathrm{~F}$-dihydroxy-phenyl-alanine and ${ }^{11} \mathrm{C}$ 5-hydroxy-tryptophan positron emission tomography. J Clin Oncol 2008 20;26:14891495.

22 Pettinato C, Sarnelli A, Di Donna M, Civollani S, Nanni C, Montini G, Di Pierro D, Ferrari M, Marengo M, Bergamini C: ${ }^{68} \mathrm{Ga}$ DOTANOC: biodistribution and dosimetry in patients affected by neuroendocrine tumors. Eur J Nucl Med 2008;35:72-79.

23 Antunes P, Ginj M, Zhang H, Waser B, Baum RP, Reubi JC, Maecke H: Are radiogalliumlabelled DOTA-conjugated somatostatin analogues superior to those labelled with other radiometals? Eur J Nucl Med 2007;34:982993.

24 Treglia G, Castaldi P, Rindi G, Giordano A, Rufini V: Diagnostic performance of gallium-68 somatostatin receptor PET and PET/ $\mathrm{CT}$ in patients with thoracic and gastroenteropancreatic neuroendocrine tumours: a meta-analysis. Endocrine 2012;42:80-87.

25 Krausz Y, Rubinstein R, Appelbaum L, Mishani E, Orevi M, Fraenkel M, Tshori S, Glaser B, Bocher M, Salmon A, Chisin R, Gross DJ, Freedman N: Ga-68 DOTA-NOC uptake in the pancreas: pathological and physiological patterns. Clin Nucl Med 2012;37:57-62.

26 Ambrosini V, Campana D, Tomassetti P, Grassetto G, Rubello D, Fanti S: PET/CT with ${ }^{68}$ Gallium-DOTA-peptides in NET: an overview. Eur J Radiol 2011;80:e116-e119.

27 Hofman MS, Kong G, Neels OC, Eu P, Hong E, Hicks RJ: High management impact of Ga68 DOTATATE (GaTate) PET/CT for imaging neuroendocrine and other somatostatin expressing tumours. J Med Imaging Radiat Oncol 2012;56:40-47.

28 Kayani I, Bomanji JB, Groves A, Conway G, Gacinovic S, Win T, Dickson J, Caplin M, Ell PJ: Functional imaging of neuroendocrine tumors with combined PET/CT using ${ }^{68} \mathrm{Ga}$ DOTATATE (DOTA-DPhe1,Tyr3-octreotate) and ${ }^{18}$ F-FDG. Cancer 2008;112:24472455. 
29 Ambrosini V, Tomassetti P, Castellucci P, Campana D, Montini G, Rubello D, Nanni C, Rizzello A, Franchi R, Fanti S: Comparison between ${ }^{68} \mathrm{Ga}$-DOTA-NOC and ${ }^{18} \mathrm{~F}$-DOPA PET for the detection of gastro-entero-pancreatic and lung neuro-endocrine tumours. Eur J Nucl Med Mol Imaging 2008;35:14311438.

-30 Ambrosini V, Nanni C, Zompatori M, Campana $\mathrm{D}$, Tomassetti $\mathrm{P}$, Castellucci $\mathrm{P}$, Allegri $\mathrm{V}$, Rubello D, Montini G, Franchi R, Fanti S: (68) Ga-DOTA-NOC PET/CT in comparison with CT for the detection of bone metastasis in patients with neuroendocrine tumours. Eur J Nucl Med Mol Imaging 2010;37:722727.

31 Kabasakal L, Demirci E, Ocak M, Decristoforo C, Araman A, Ozsoy Y, Uslu I, Kanmaz B: Comparison of ${ }^{68} \mathrm{Ga}$-DOTATATE and ${ }^{68} \mathrm{Ga}$-DOTANOC PET/CT imaging in the same patient group with neuroendocrine tumours. Eur J Nucl Med Mol Imaging 2012;39: 1271-1277.

-32 Gotthardt M, Béhé MP, Grass J, Bauhofer A, Rinke A, Schipper ML, Kalinowski M, Arnold R, Oyen WJ, Behr TM: Added value of gastrin receptor scintigraphy in comparison to somatostatin receptor scintigraphy in patients with carcinoids and other neuroendocrine tumors. Endocr Relat Cancer 2006;13:12031211.

33 Brom M, Joosten L, Laverman P, Oyen WJ, Béhé M, Gotthardt M, Boerman OC: Preclinical evaluation of ${ }^{68} \mathrm{Ga}$-DOTA-minigastrin for the detection of cholecystokinin-2/gastrin receptor-positive tumors. Mol Imaging 2011; 10:144-152.
34 Wild D, Mäcke H, Christ E, Gloor B, Reubi JC: Glucagon-like peptide 1-receptor scans to localize occult insulinomas. N Engl J Med 2008; 359:766-768.

35 Christ E, Wild D, Forrer F, Brändle M, Sahli $\mathrm{R}$, Clerici T, et al: Glucagon-like peptide 1-receptor imaging for localization of insulinomas. J Clin Endocrinol Metab. 2009;94:43984405.

36 Wild D, Christ E, Caplin ME, Kurzawinski TR, Forrer F, Brändle $M$, Seufert J, Weber WA, Bomanji J, Perren A, Ell PJ, Reubi JC: Glucagon-like peptide-1 versus somatostatin receptor targeting reveals 2 distinct forms of malignant insulinomas. J Nucl Med 2011;52: 1073-1078.

37 Sowa-Staszczak A, Pach D, Mikołajczak R, Mäcke H, et al: Glucagon-like peptide-1 receptor imaging with $\left[\mathrm{Lys}^{40}(\mathrm{Ahx}-\mathrm{HYNIC}\right.$ $\left.{ }^{99 \mathrm{~m}} \mathrm{Tc} / \mathrm{EDDA}\right) \mathrm{NH}_{2}$ ]-exendin-4 for the detection of insulinoma. Eur J Nucl Med Mol Imaging 2013;40:524-531.

38 Wicki A, Wild D, Storch D, Seemayer C, Gotthardt M, Behe M, et al: [Lys40 (AhxDTPA-111In) NH2]-exendin-4 is a highly efficient radiotherapeutic for glucagon-like peptide-1 receptor targeted therapy for insulinoma. Clin Cancer Res 2007;13:3696-3705.
39 Srirajaskanthan R, Kayani I, Quigley AM, Soh J, Caplin ME, Bomanji J: The role of ${ }^{68} \mathrm{Ga}-$ DOTATATE PET in patients with neuroendocrine tumors and negative or equivocal findings on ${ }^{111} \mathrm{In}$-DTPA-octreotide scintigraphy. J Nucl Med 2010;51:875-882.

40 Savelli G, Lucignani G, Seregni E, Marchianò A, Serafini G, Aliberti G, Villano C, Maccauro M, Bombardieri E: Feasibility of somatostatin receptor scintigraphy in the detection of occult primary gastro-entero-pancreatic (GEP) neuroendocrine tumours. Nucl Med Commun 2004;25:445-449.

41 Prasad V, Ambrosini V, Hommann M, Hoersch D, Fanti S, Baum RP: Detection of unknown primary neuroendocrine tumours (CUP-NET) using (68)Ga-DOTA-NOC receptor PET/CT. Eur J Nucl Med Mol Imaging 2010;37:67-77.

42 Ambrosini V, Campana D, Nanni C, Cambioli S, Tomassetti P, Rubello D, Fanti S: Is ${ }^{68} \mathrm{Ga}$-DOTA-NOC PET/CT indicated in patients with clinical, biochemical or radiological suspicion of neuroendocrine tumour? Eur J Nucl Med Mol Imaging 2012;39:1278-1283.

43 Modlin IM, Lye KD, Kidd M: A 5-decade analysis of 13,715 carcinoid tumors. Cancer 2003;97:934-959.

44 Desai K, Watkins J, Woodward N, Quigley AM, Toumpanakis C, Bomanji J, Caplin M: Use of molecular imaging to differentiate liver metastasis of colorectal cancer metastasis from neuroendocrine tumor origin. J Clin Gastroenterol 2011;45:e8-e11. 